\title{
Endoscopic third ventriculostomy for pediatric tumor-associated hydrocephalus
}

\author{
Brandon A. Sherrod, MD, Rajiv R. lyer, MD, and John R. W. Kestle, MD \\ Department of Neurosurgery, University of Utah, and Primary Children's Hospital, Salt Lake City, Utah
}

\begin{abstract}
OBJECTIVE Surgical options for managing hydrocephalus secondary to CNS tumors have traditionally included ventriculoperitoneal shunting (VPS) when tumor resection or medical management alone are ineffective. Endoscopic third ventriculostomy (ETV) has emerged as an attractive treatment strategy for tumor-associated hydrocephalus because it offers a lower risk of infection and hardware-related complications; however, relatively little has been written on the topic of ETV specifically for the treatment of tumor-associated hydrocephalus. Here, the authors reviewed the existing literature on the use of ETV in the treatment of tumor-associated hydrocephalus, focusing on the frequency of ETV use and the failure rates in patients with hydrocephalus secondary to CNS tumor.
\end{abstract}

METHODS The authors queried PubMed for the following terms: "endoscopic third ventriculostomy," "tumor," and "pediatric." Papers with only adult populations, case reports, and papers published before the year 2000 were excluded. The authors analyzed the etiology of hydrocephalus and failure rates after ETV, and they compared failure rates of ETV with those of VPS where reported.

RESULTS Thirty-two studies with data on pediatric patients undergoing ETV for tumor-related hydrocephalus were analyzed. Tumors, particularly in the posterior fossa, were reported as the etiology of hydrocephalus in $38.6 \%$ of all ETVs performed (984 of $2547 \mathrm{ETVs}$, range $29 \%-55 \%$ ). The ETV failure rate in tumor-related hydrocephalus ranged from $6 \%$ to $38.6 \%$, and in the largest studies analyzed (> 100 patients), the ETV failure rate ranged from $10 \%$ to $38.6 \%$. The pooled ETV failure rate was 18.3\% (199 failures after 1087 procedures). The mean or median follow-up for ETV failure assessment ranged from 6 months to 8 years in these studies. Only 5 studies directly compared ETV with VPS for tumor-associated hydrocephalus, and they reported mixed results in regard to failure rate and time to failure. Overall failure rates appear similar for ETV and VPS over time, and the risk of infection appears to be lower in those patients undergoing ETV. The literature is mixed regarding the need for routine ETV before resection for posterior fossa tumors with associated hydrocephalus.

CONCLUSIONS Treatment of tumor-related hydrocephalus with ETV is common and is warranted in select pediatric patient populations. Failure rates are overall similar to those of VPS for tumor-associated hydrocephalus.

https://thejns.org/doi/abs/10.3171/2019.10.FOCUS19725

KEYWORDS tumor-associated hydrocephalus; endoscopic third ventriculostomy; pediatric

$\mathrm{H}$ YDROCEPHALUS is one of the most common pathologies requiring neurosurgical intervention in children. Managing hydrocephalus due to pediatric CNS tumors presents a complex and challenging problem..$^{39}$ Postresection hydrocephalus occurs in approximately $30 \%$ of children with posterior fossa tumors, and obstructive hydrocephalus is present in approximately $80 \%$ of pediatric patients with posterior fossa tumors. ${ }^{9,26}$ Surgical options for addressing hydrocephalus have traditionally included ventriculoperitoneal shunting (VPS) when tumor resection and/or medical management alone are ineffective. Endoscopic third ventriculostomy (ETV) was initially described in 1923 by William Mixter ${ }^{25}$ as a treatment strategy for hydrocephalus and has appeal as a method to reduce the risk of introducing hardware-related infectious complications in children who need surgical treatment for hydrocephalus. Numerous studies have compared ETV and VPS in regard to efficacy and infection rates in treatment of pediatric hydrocephalus in general, with the consensus being that ETV reduces procedural

ABBREVIATIONS ETV = endoscopic third ventriculostomy; ETVSS = ETV Success Score; VPS = ventriculoperitoneal shunting.

SUBMITTED September 6, 2019. ACCEPTED October 14, 2019.

INCLUDE WHEN CITING DOI: 10.3171/2019.10.FOCUS19725. 


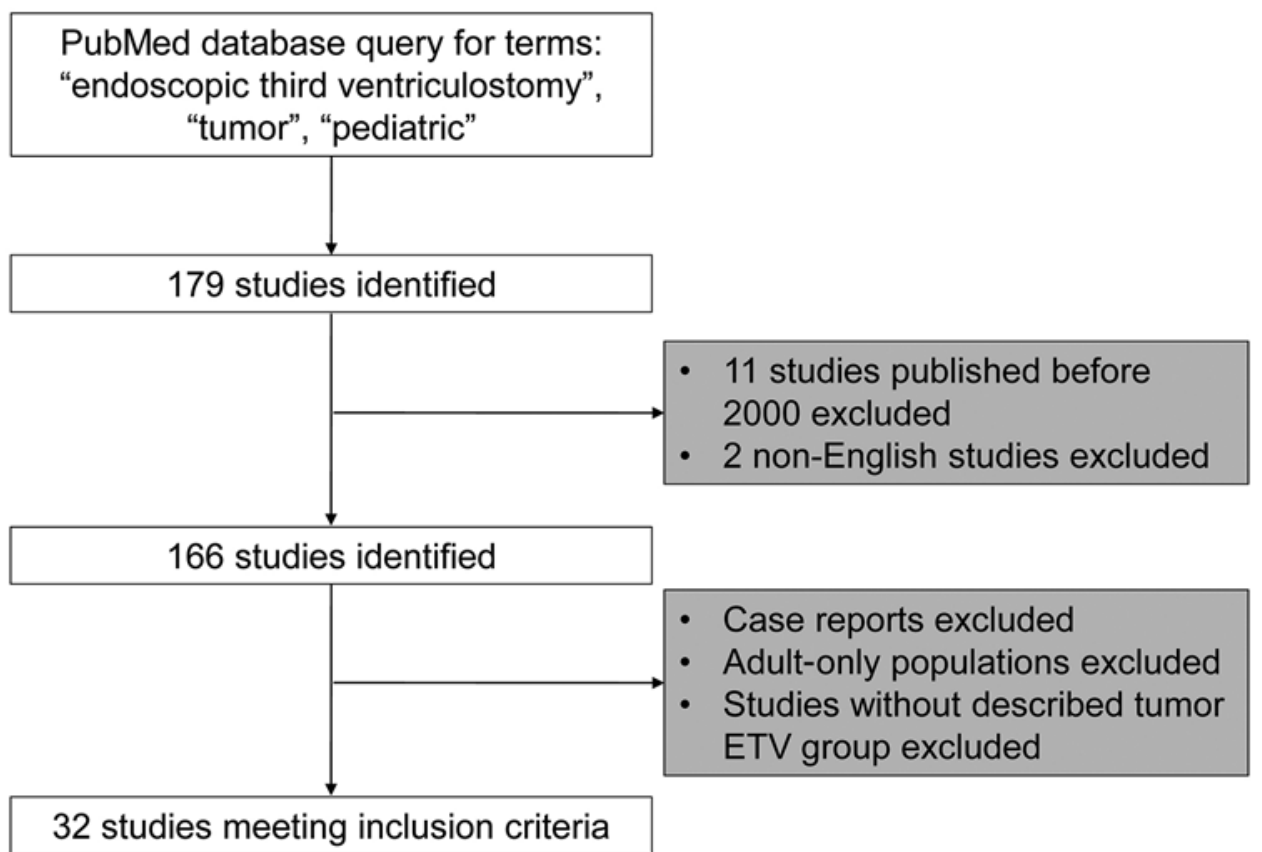

FIG. 1. PRISMA diagram of the literature search and selection process.

infection risk, but the overall reoperation rates for recurrent hydrocephalus are equivalent between ETV and VPS. ${ }^{15,21,38}$ However, relatively little has been written specifically about the use of ETV in the pediatric CNS tumor population.

Here, we review the existing literature on ETV in the treatment of tumor-associated hydrocephalus, paying specific attention to the frequency of ETV use in this clinical scenario and the failure rates of preresection ETV in patients with hydrocephalus secondary to CNS tumors.

\section{Methods}

We queried PubMed in August 2019 for the following terms: "endoscopic third ventriculostomy," "tumor," and "pediatric." We excluded papers that evaluated only adult (age 18 years and older) populations, but we included mixed adult and pediatric population studies if analysis of the pediatric population was reported separately. We also excluded papers published before 2000 and case reports. Results were filtered for English-language literature. Even if the primary aim of the study in question was not tumorrelated hydrocephalus, we analyzed subpopulations in papers that reported tumor as a cause for hydrocephalus.

Data were collected on hydrocephalus etiology or indication for ETV, study type (prospective cohort, retrospective cohort, or systematic review/meta-analysis), year of data collection, ETV failure rates, mean postoperative follow-up, and comparison of outcomes between ETV and VPS, if reported. Linear regression was used to analyze the effect of study publication year on ETV failure rate. Pooled calculations for frequency of ETV for tumor-associated hydrocephalus etiology and for ETV failure rates over multiple studies (excluding systemic reviews and meta-analyses) were performed.

\section{Results}

The initial search query yielded 179 study results. Of the initial 179 results, only 168 studies were published in 2000 or later. Of these, 166 were studies written in the English language, 32 of which met the inclusion criteria (Fig. 1).

Thirty-two studies with data on pediatric patients undergoing ETV for tumor-related hydrocephalus were analyzed, ${ }^{1-4,6-10,12,13,15-24,26-31,34-38}$ including 3 systematic literature reviews, 3 international prospective cohort studies, 2 multiinstitutional prospective cohort studies, and 24 retrospective or prospective single-institution studies.

\section{Frequency of ETV for Hydrocephalus Secondary to CNS Tumors}

Table 1 displays a summary of the literature on frequency of ETV use for tumor-associated hydrocephalus. The cause of hydrocephalus was neoplasia in $29 \%$ to $55 \%$ of ETV cases analyzed. In the largest studies (> 1000 patients), the cause of hydrocephalus was neoplasia in approximately $35 \%$ of ETV cases. The overall pooled frequency from all primary studies (excluding review articles) was $38.6 \%$, whereas the mean $( \pm \mathrm{SD})$ frequency was $39.5 \% \pm 9.0 \%$. Few studies reported the percentage of tumor by subtypes, but in the studies that did so, posterior fossa tumors and midbrain/tectal tumors were the most common subtype.

\section{ETV Failure Rates in Tumor-Related Hydrocephalus}

Table 2 displays a summary of the literature that reported ETV failure rates for tumor-related hydrocephalus. In the largest studies analyzed ( $>100$ patients undergoing ETV for tumor-related hydrocephalus), the failure rate of ETV ranged from $10 \%$ to $38.6 \%$. Overall, failure rates 
TABLE 1. Frequency of ETV use for tumor-associated hydrocephalus

\begin{tabular}{|c|c|c|c|c|}
\hline $\begin{array}{l}\text { Authors \& } \\
\text { Year }\end{array}$ & Design, Level of Evidence & Pt Population & Frequency & Tumor Subtype/Location \\
\hline $\begin{array}{l}\text { Madsen et al., } \\
2018\end{array}$ & $\begin{array}{l}\text { Systematic literature review } \\
\text { (130 studies), level } \text { III* }^{*}\end{array}$ & $\begin{array}{l}\text { 11,952 ETVs in children w/ any-cause } \\
\text { hydrocephalus }\end{array}$ & $\begin{array}{l}\text { Pooled mean: } 34.1 \% \\
\quad \text { (SD } 17.2 \%)\end{array}$ & NR \\
\hline $\begin{array}{l}\text { Bouras \& } \\
\text { Sgouros, } \\
2011\end{array}$ & $\begin{array}{l}\text { Systematic literature review } \\
\text { (34 studies), level III* }\end{array}$ & $\begin{array}{l}2985 \text { ETVs in } 2884 \text { adult \& pediatric pts } \\
\text { for any-cause hydrocephalus }\end{array}$ & $37.6 \%$ & NR \\
\hline $\begin{array}{l}\text { Kulkarni et al., } \\
2016\end{array}$ & $\begin{array}{l}\text { International prospective } \\
\text { cohort, level II }\end{array}$ & $\begin{array}{l}336 \text { pts who had ETV for any-cause } \\
\text { hydrocephalus }\end{array}$ & $137(41.0 \%)$ & $\begin{array}{l}21.2 \% \text { midbrain; } 14.4 \% \text { posterior } \\
\quad \text { fossa; } 5.4 \% \text { supratentorial }\end{array}$ \\
\hline $\begin{array}{l}\text { Lam et al., } \\
\qquad 2014\end{array}$ & $\begin{array}{l}\text { National database retro- } \\
\text { spective review, level III }\end{array}$ & 501 pts who had ETV for any cause & $209(41.7 \%)$ & NR \\
\hline $\begin{array}{l}\text { Kulkarni et al., } \\
2010^{15}\end{array}$ & $\begin{array}{l}\text { International prospective } \\
\text { cohort, level II }\end{array}$ & $\begin{array}{l}1209 \text { pts who had ETV }(n=489) \text { or VPS } \\
(n=720) \text { for any-cause hydrocephalus }\end{array}$ & $\begin{array}{l}175(35.8 \% \text { of all } \\
\text { ETVs) }\end{array}$ & NR \\
\hline $\begin{array}{l}\text { Naftel et al., } \\
2011\end{array}$ & $\begin{array}{l}\text { Single-institution consecu- } \\
\text { tive case series, level IV }\end{array}$ & 151 pts who had ETVs btwn 1995 \& 2009 & $72(47.7 \%)$ & $\begin{array}{l}5(6.9 \%) \text { supratentorial; } 46(63.9 \%) \\
\quad \text { midbrain; } 21(29.2 \%) \text { posterior fossa }\end{array}$ \\
\hline $\begin{array}{l}\text { Kulkarni et al., } \\
2009\end{array}$ & $\begin{array}{l}\text { International cohort from } 12 \\
\text { institutions, level II }\end{array}$ & 618 pts who had ETV for any cause & $182(29.4 \%)$ & $\begin{array}{l}62(34.1 \%) \text { midbrain tectal; } 120 \\
\quad(65.9 \%) \text { nontectal }\end{array}$ \\
\hline $\begin{array}{l}\text { Beuriat et al., } \\
2017\end{array}$ & $\begin{array}{l}\text { Single-institution retrospec- } \\
\text { tive review, level III }\end{array}$ & $\begin{array}{l}975 \text { pts treated for hydrocephalus; } 280 \\
\text { pts who had ETV }\end{array}$ & $155(55.4 \%)$ & NR \\
\hline $\begin{array}{l}\text { Feng et al., } \\
2004\end{array}$ & $\begin{array}{l}\text { Single-institution retrospec- } \\
\text { tive review, level III }\end{array}$ & $\begin{array}{l}58 \text { pts who had ETV for any-cause } \\
\text { hydrocephalus }\end{array}$ & $21(36.2 \%)$ & NR \\
\hline $\begin{array}{l}\text { Furlanetti et } \\
\quad \text { al., } 2012\end{array}$ & $\begin{array}{l}\text { Consecutive case series, } \\
\text { level IV }\end{array}$ & $\begin{array}{l}114 \text { pediatric pts who had ETV for any- } \\
\text { cause hydrocephalus }\end{array}$ & $33(28.9 \%)$ & NR \\
\hline
\end{tabular}

NR = not reported; $p t=$ patient.

* Data presented from systemic reviews were not included in the overall calculations of pooled/mean frequencies of ETV for tumor-associated hydrocephalus. The overall pooled/mean frequency calculations are derived from primary studies only.

ranged from $6 \%$ to $38.6 \%$. The overall pooled failure rate from all primary studies (excluding review articles) was $18.3 \%$, whereas the mean $( \pm$ SD) failure rate was $17.4 \%$ $\pm 8.6 \%$. Postoperative follow-up ranged from 6 months to 8 years. Timing of ETV (pre- vs postresection ETV) and tumor subtype by study are shown.

Figure 2 displays failure rates by publication year of each study. No difference in failure rate by study year was seen on linear regression analysis $\left(\mathrm{R}^{2}=0.016, \mathrm{p}=0.61\right)$.

\section{Comparison of ETV and VPS Failure Rates for Tumor-Associated Hydrocephalus}

Table 3 compares failure rates and time to failure for ETV versus VPS in pediatric patients with tumor-associated hydrocephalus. There were only 5 studies with direct comparison of ETV versus VPS specifically for tumorassociated hydrocephalus. Two studies (those by El-Ghandour $^{7}$ and Beuriat et al. ${ }^{1}$ ) reported a significantly lower failure rate with ETV than with VPS, whereas 3 studies (those by Dewan et al., ${ }^{4}$ Sainte-Rose et al., ${ }^{35}$ and Ruggiero et $a .^{34}$ ) did not report significantly lower ETV failure rates compared with VPS. Regarding time to failure, Dewan et al. ${ }^{4}$ reported a significantly shorter time to failure for ETV than for VPS $(p=0.03)$, whereas El-Ghandour ${ }^{7}$ did not find a significant difference in time to failure.

\section{Discussion}

As enthusiasm for the use of ETV in the treatment of hydrocephalus as a whole has grown, understanding the benefits of ETV in tumor-associated hydrocephalus may improve overall outcomes. Here, we have reviewed the literature on ETV in tumor-related hydrocephalus, including the relative frequency of ETV use in patients with this disorder and the failure rates of ETV in this population. Tumors, particularly in the posterior fossa, were reported as the etiology of hydrocephalus in $29 \%$ to $55 \%$ of all ETVs performed. The ETV failure rate ranged from $10 \%$ to $38.6 \%$ in the largest studies analyzed. No differences were observed for failure rate by study year. Only 5 studies directly compared ETV with VPS for tumor-associated hydrocephalus, and they reported mixed results regarding superiority in regard to failure rate and time to failure.

\section{Frequency of ETV for Tumor-Related Hydrocephalus}

Tumor was the etiology of hydrocephalus in $29 \%-55 \%$ of ETV cases in the studies reported. Two systematic literature reviews, one by Bouras and Sgouros ${ }^{3}$ and the other by Madsen et al., ${ }^{23}$ demonstrated that $34.1 \% \pm 17.2 \%$ (pooled mean $\pm \mathrm{SD}$ ) and $37.6 \%$ of pediatric ETVs, respectively, were performed for tumor-associated hydrocephalus. These findings are similar to those that Kulkarni et al. ${ }^{15}$ found in an international prospective cohort $(35.8 \%$ of all ETVs were for tumor-related hydrocephalus). Slightly higher rates were reported by Lam et al. ${ }^{19}$ (41.7\% of patients in the cohort), Beuriat et al. ${ }^{1}(55.4 \%)$, and Naftel et $\mathrm{al}^{28}(47.7 \%)$. Generally, the rates of ETV use for tumorrelated hydrocephalus have not increased over time. The 


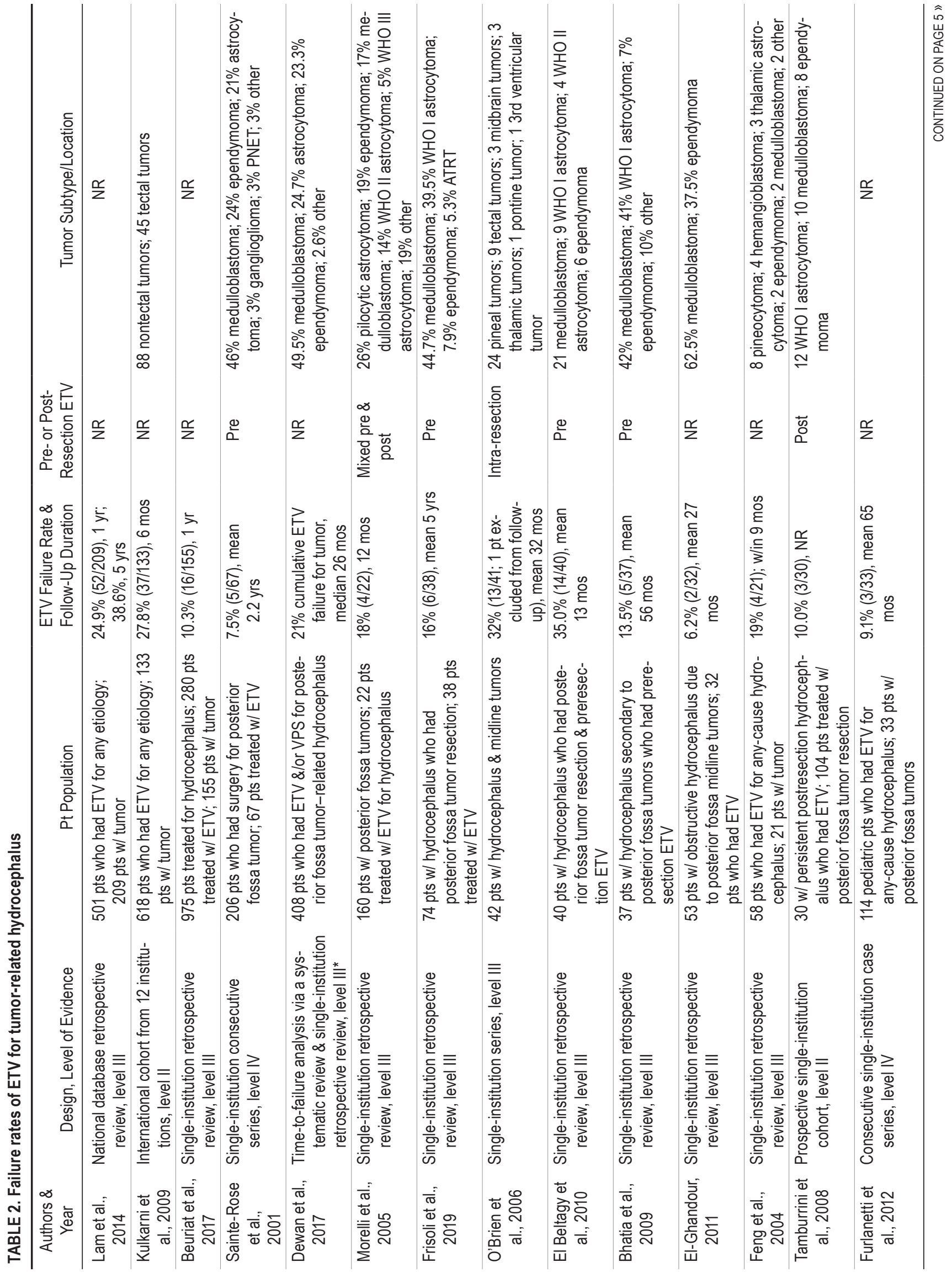




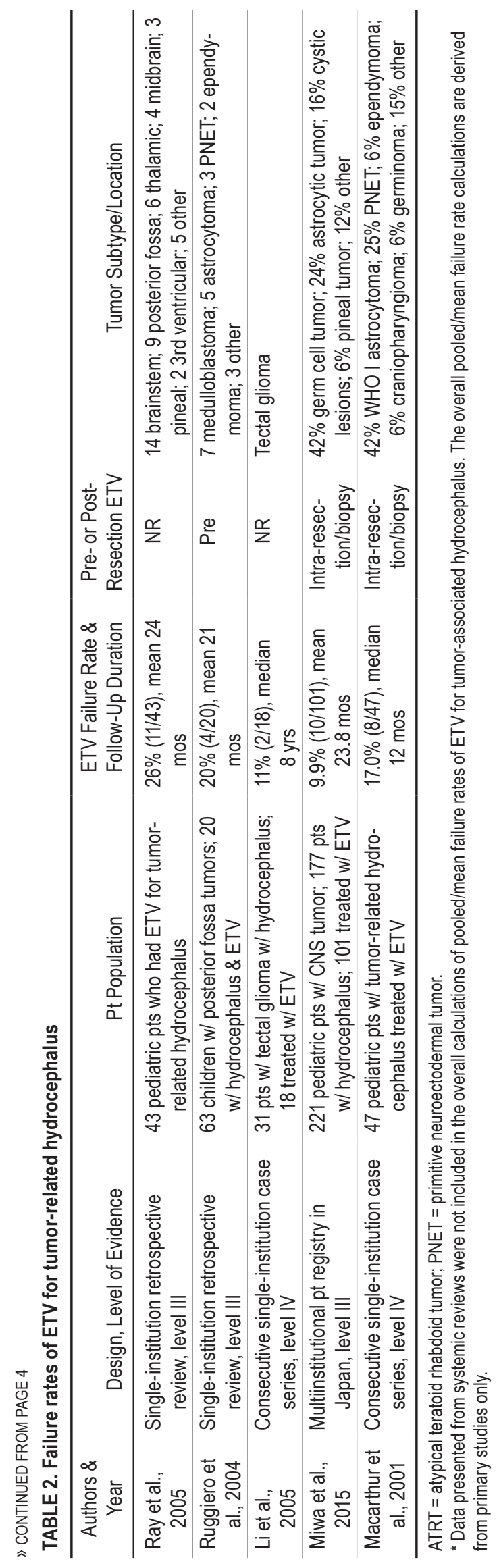

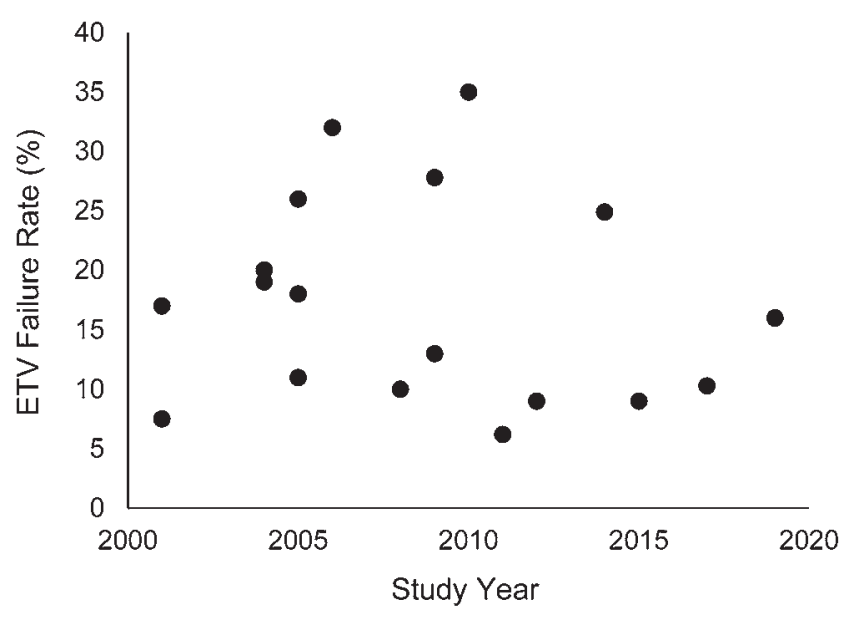

FIG. 2. ETV failure rate for tumor-associated hydrocephalus by publication year of each study (excludes data from meta-analyses/systemic reviews). Linear regression analysis demonstrated no significant difference in failure rate by year $(p=0.61)$.

rates of ETV reported in these studies for various locations or tumor subtypes varied substantially.

\section{ETV Failure in Tumor-Related Hydrocephalus}

In the largest studies analyzed (> 100 patients undergoing ETV for tumor-related hydrocephalus), the failure rate of ETV ranged from $10 \%$ to $38.6 \% .^{4,17,19}$ Overall, failure rates ranged from $6 \%$ to $35 \%$. ETV failure generally occurs quickly (within the first 3 months) but then the failure rate plateaus. ${ }^{4}$ These failure rates are overall unsurprising and provide a frame of reference with which to counsel patients and families regarding the expected outcomes of ETV surgery.

Lam et al. ${ }^{19}$ analyzed the national MarketScan database from 2003 to 2011 and determined that of the 209 patients with tumor-associated hydrocephalus who underwent ETV, $157(75.1 \%)$ of the procedures were successful at 1 year. Furthermore, the 5-year success rate for ETV in this population of patients was $61.4 \%$. The 5 -year success rate for ETV in children with tumor-associated hydrocephalus was also found to be similar to that for other causes of hydrocephalus $(65.5 \%$ with myelomeningocele, $52.3 \%$ with congenital etiologies).

Kulkarni et al. ${ }^{17}$ reported data from an international cohort from 12 institutions. The authors included 618 patients who underwent ETV for any cause, 29.4\% of whom (182 patients of 618 total) underwent ETV for tumor-related hydrocephalus. Ninety-six (72.2\%) of 133 patients who underwent ETV for tumor-related hydrocephalus had treatment success at 6 months. Tectal tumors were associated with a higher ETV success rate at 6 months than nontectal tumors (82.2\% vs $67.0 \%)$. Sainte-Rose et al. ${ }^{35}$ reported a single-institution consecutive series of 206 patients, of whom 196 underwent surgery for treatment of hydrocephalus due to posterior fossa tumors. The authors stratified their population into 3 groups: 67 patients who underwent preresection ETV because hydrocephalus was present on admission (group A); 82 patients who had 
TABLE 3. Comparison of failure rates of ETV and VPS for tumor-associated hydrocephalus

\begin{tabular}{|c|c|c|c|c|c|c|c|c|c|}
\hline \multirow{2}{*}{$\begin{array}{c}\text { Authors \& } \\
\text { Year }\end{array}$} & \multirow{2}{*}{$\begin{array}{c}\text { Design, Level of } \\
\text { Evidence }\end{array}$} & \multirow[b]{2}{*}{ Pt Population } & \multirow{2}{*}{$\begin{array}{l}\text { Length of } \\
\text { Follow-Up }\end{array}$} & \multicolumn{3}{|c|}{ Failure Rate } & \multicolumn{3}{|c|}{ Time to Failure (mos) } \\
\hline & & & & ETV & VPS & $p$ Value & ETV & VPS & $p$ Value \\
\hline $\begin{array}{l}\text { Dewan et al., } \\
2017\end{array}$ & $\begin{array}{l}\text { Systematic review \& } \\
\text { single-institution } \\
\text { retrospective } \\
\text { review, level III }\end{array}$ & $\begin{array}{l}408 \text { pts undergoing ETV \&/or VPS } \\
\text { for posterior fossa tumor-re- } \\
\text { lated hydrocephalus }\end{array}$ & $\begin{array}{l}\text { Median } 26 \\
\text { mos }\end{array}$ & $21 \%$ & $29 \%$ & 0.105 & $\begin{array}{c}\text { Median } \\
0.82\end{array}$ & $\begin{array}{c}\text { Median } \\
\quad 4.7\end{array}$ & 0.03 \\
\hline $\begin{array}{l}\text { Beuriat et al., } \\
2017\end{array}$ & $\begin{array}{l}\text { Retrospective } \\
\text { review of single- } \\
\text { institution cohort, } \\
\text { level III }\end{array}$ & $\begin{array}{l}975 \text { pts treated for hydrocephalus; } \\
280 \text { pts treated w/ ETV (155 for } \\
\text { tumor-related hydrocephalus); } \\
695 \text { pts treated w/ VPS (160 for } \\
\text { tumor-related hydrocephalus) }\end{array}$ & $1 \mathrm{yr}$ & $\begin{array}{c}10.3 \% \\
(16 / 155)\end{array}$ & $\begin{array}{c}38.8 \% \\
(62 / 160)\end{array}$ & $<0.001$ & NR & NR & NR \\
\hline $\begin{array}{l}\text { El-Ghandour, } \\
2011\end{array}$ & $\begin{array}{l}\text { Single-institution } \\
\text { retrospective } \\
\text { review, level III }\end{array}$ & $\begin{array}{l}53 \text { pts w/ obstructive hydro- } \\
\text { cephalus due to posterior fossa } \\
\text { midline tumors }\end{array}$ & $\begin{array}{l}\text { ETV: mean } \\
27 \text { mos; } \\
\text { VPS: } \\
\text { mean } 25 \\
\text { mos }\end{array}$ & $\begin{array}{l}6.2 \% \\
(2 / 32)\end{array}$ & $\begin{array}{l}38 \% \\
(8 / 21)\end{array}$ & 0.003 & $\begin{array}{c}\text { Mean } \\
10.3\end{array}$ & $\begin{array}{c}\text { Mean } \\
5.6\end{array}$ & 0.2 \\
\hline $\begin{array}{l}\text { Sainte-Rose } \\
\text { et al., } 2001\end{array}$ & $\begin{array}{l}\text { Single-institution } \\
\text { consecutive } \\
\text { series, level IV }\end{array}$ & $\begin{array}{l}206 \text { pts who had posterior fossa } \\
\text { tumor resection; } 67 \text { undergoing } \\
\text { ETV; } 16 \text { undergoing VPS }\end{array}$ & $\begin{array}{l}\text { Mean } 2.2 \\
\text { yrs }\end{array}$ & $\begin{array}{l}7.5 \% \\
(5 / 67)\end{array}$ & $\begin{array}{l}12.5 \% \\
(2 / 16)\end{array}$ & 0.61 & NR & NR & NR \\
\hline $\begin{array}{l}\text { Ruggiero et } \\
\text { al., } 2004\end{array}$ & $\begin{array}{l}\text { Single-institution } \\
\text { retrospective } \\
\text { review, level III }\end{array}$ & $\begin{array}{l}63 \text { children w/ posterior fossa } \\
\text { tumors; } 20 \text { undergoing ETV; } 4 \\
\text { undergoing VPS }\end{array}$ & $\begin{array}{c}\text { Mean } 21 \\
\text { mos }\end{array}$ & $\begin{array}{l}20 \% \\
(4 / 20)\end{array}$ & $0 \%(0 / 4)$ & NR & $\begin{array}{c}\text { Mean } \\
0.9\end{array}$ & NR & NR \\
\hline
\end{tabular}

hydrocephalus present on admission but did not undergo ETV before resection (group B); and 47 patients who did not have evidence of preresection hydrocephalus (group C). In group A, 4 patients (6.0\%) required VPS postresection and 1 patient required repeat ETV. In group B, 16 $(19.5 \%)$ required VPS postresection $(p<0.02$ compared with group A). No VP shunts were inserted in the group C population. Importantly, there were significant differences between groups $\mathrm{A}, \mathrm{B}$, and $\mathrm{C}$ with regard to anatomical tumor location and subtype (e.g., group A had more midline tumors and medulloblastomas compared with groups B and C).

Frisoli et al..$^{10}$ performed a retrospective review of 74 patients presenting with hydrocephalus who underwent posterior fossa tumor resection between 2005 and 2016. Pineal and tectal tumors were excluded. The most common tumor subtype was medulloblastoma (48.6\%) followed by low-grade astrocytoma (35.1\%). The 38 patients who underwent preresection ETV were compared with 36 historical control patients who underwent tumor resection but no preoperative or perioperative ETV. The rate of postoperative VPS was $31 \%$ in the non-ETV group compared with $16 \%$ in the ETV group ( $\mathrm{p}=0.131)$.

\section{ETV Versus VPS in Tumor-Related Hydrocephalus}

Numerous studies have compared ETV and VPS for treatment of pediatric hydrocephalus generally, ${ }^{15,16,38}$ but few have specifically compared the two treatments for tumor-related hydrocephalus specifically. Dewan et al. ${ }^{4}$ conducted time-to-failure analysis of ETV and VPS for hydrocephalus secondary to posterior fossa tumors via a systematic review and single-institution retrospective review. The study included 408 patients, 284 of whom were from the authors' institution. The cumulative failure rates were statistically similar for ETV and VPS, but the median time to failure was earlier for ETV than for VPS (0.82 [IQR 0.2-1.8] months vs 4.7 [IQR 0.3-5.7] months, $\mathrm{p}=0.03)$. In the time-to-failure analysis, the ETV survival curve dropped sharply and then plateaued about 2 months postoperatively, whereas the VPS survival curve fell gradually but then crossed below the ETV curve at 5.7 months postoperatively $(\mathrm{p}=0.21, \log$-rank test). The authors concluded that ETV failure occurred before VPS failure, but long-term success may be similar or higher for ETV. El-Ghandour ${ }^{7}$ also compared ETV and VPS for posterior fossa tumor-related hydrocephalus in 53 pediatric patients, finding ETV to be superior to VPS because of the shorter length of surgery (15 minutes vs 35 minutes), lower morbidity ( $9.3 \%$ vs $38 \%)$, reduced mortality ( $0 \%$ vs $4.7 \%)$, and lower incidence of failure (6.2\% vs $38 \%$ ). The ETV failure rate at a 27 -month mean follow-up was $6.2 \%$ versus a VPS failure rate of $38 \%$ at a 25 -month mean follow-up $(\mathrm{p}=0.003)$. Sainte-Rose et al. ${ }^{35}$ reported an ETV failure rate of $7.5 \%$ at follow-up of 2.2 years versus a VPS failure rate of $12.5 \%$ at the same follow-up duration $(p=0.61)$ in patients with hydrocephalus secondary to posterior fossa tumor. Given the dearth of literature in this subpopulation of patients undergoing ETV, future prospective studies investigating efficacy and safety of ETV versus VPS in patients with tumor-related hydrocephalus are warranted. ${ }^{14}$

Although Riva-Cambrin et al. ${ }^{32}$ did not analyze patients undergoing ETV, in 2016 the authors did analyze cause of VPS failure in the largest prospective study to date in 1036 children undergoing VPS placement. The rates of VPS failure were $29.3 \%$ in the posterior fossa tumor group and $30.1 \%$ in the "other" tumor group at a median follow- 
up of 264 days. The failure rates they observed in children undergoing VPS for tumor-associated hydrocephalus are relatively similar to the ETV failure rates for children undergoing ETV for tumor hydrocephalus reported in the largest studies found in our current review (10\%-38.6\%).

\section{Predictors of Good Outcome After Preresection ETV}

In 2009, Riva-Cambrin et al. ${ }^{31}$ published a scoring system to predict those pediatric patients who would require CSF diversion after posterior fossa tumor resection. The score consisted of 10 points: 3 points for age $<2$ years, 3 points for cerebral metastases, 2 points for moderate or severe hydrocephalus, 1 point for papilledema, and 1 point for preoperative radiographic features consistent with an ependymoma, dorsally exophytic brainstem glioma, or medulloblastoma. High-risk patients were those with scores $>4$ points, and low-risk patients were those with scores of $0-2$. The rate of postoperative CSF diversion was $73 \%$ for high-risk patients and $25 \%$ for low-risk patients. Foreman et al. ${ }^{9}$ published a modified version of the success score published by Riva-Cambrin et al. ${ }^{31}$ in a cohort of 76 patients, finding that 4 variables were significant in predicting postresection hydrocephalus: age $<2$ years, moderate/severe hydrocephalus, preoperative tumor diagnosis, and transependymal edema.

The original ETV Success Score (ETVSS) published by Kulkarni et al. ${ }^{17}$ was developed to predict which pediatric patients would have the highest chance of hydrocephalus treatment success with ETV and was later validated in a multicenter cohort of 489 patients who underwent ETV. ${ }^{16}$ The ETVSS is an estimate of the percentage probability of ETV success, ranging from $0 \%$ to $90 \%$ probability. There are 3 primary components: age, etiology, and history of previous shunt. Tumors are considered within the etiology component, with nontectal tumors adding $20 \%$ to the ETVSS, and tectal tumors adding $30 \%$ to the ETVSS. Overall, tumors portend a favorable increase in the ETVSS compared with other etiologies.

\section{Complications of ETV}

In the meta-analysis by Madsen and colleagues, ${ }^{23}$ complications related to ETV were reported, although those specifically related to tumor-associated hydrocephalus were not analyzed. Overall perioperative mortality was $0.2 \% \pm 0.1 \%$, and the mean ETV failure rate was $34.7 \%$ $\pm 18.0 \%$.

Texakalidis et al. ${ }^{38}$ performed a meta-analysis comparing ETV and VPS for pediatric hydrocephalus including 8419 patients (not specifically for tumor-associated hydrocephalus), finding that infection was significantly lower in the ETV group (OR 0.19, 95\% CI 0.07-0.53) but that mortality, postoperative CSF leakage, and reoperation rates were similar between groups.

Bouras and Sgouros $^{3}$ performed a systematic literature review including 2985 ETVs performed in 2884 patients from 34 studies. Importantly, the population included for this review was mixed (adult and pediatric). The early postoperative mortality rate was $0.21 \%$. The overall complication rate was $8.5 \%$. The rate of intraoperative hemorrhage was $3.7 \%$, and the rate of severe intraoperative hemorrhage was $0.6 \%$ (including a $0.21 \%$ rate of basilar rupture).
Macarthur et al. ${ }^{22}$ published a detailed report of complications encountered in 61 neuroendoscopic procedures for pediatric CNS tumors, 47 of which were ETVs for tumor-associated hydrocephalus. Only 1 death, 6 intraoperative hemorrhages, 4 CSF fistulas, and 1 deep infection occurred, and 9 extraventricular drains were required for temporary CSF diversion postoperatively.

El-Ghandour ${ }^{7}$ analyzed complications related to ETV in a posterior fossa tumor cohort, reporting no mortality in 32 patients who underwent ETV, 1 case $(3.1 \%)$ of CSF leak, and 2 cases (6.2\%) of bleeding. Ray et al. ${ }^{30}$ also analyzed ETV complications in a pediatric tumor-related hydrocephalus cohort, finding a total complication rate of $20.9 \%$ in 43 ETVs, including 1 infection and 3 cases of venous bleeding.

\section{Patient Selection for ETV in Tumor-Related Hydrocephalus}

Controversy exists regarding the necessity of default preresection ETV in posterior fossa tumor-related hydrocephalus. ${ }^{5}$ Fritsch et al. ${ }^{11}$ reported that in a single-institution series of 58 patients with posterior fossa tumors, 52 presented with hydrocephalus, but only 6 patients $(11.5 \%)$ required permanent treatment for hydrocephalus at a mean follow-up of 25 months. Of those 6, 4 patients received a VP shunt and 2 patients underwent ETV. Morelli et al. ${ }^{26}$ posed a similar question of the necessity of ETV in posterior fossa tumor-related hydrocephalus, finding that routine postoperative ETV may be beneficial in the treatment of persistent hydrocephalus, but not prophylactically, given that only $22(13.8 \%)$ of 160 patients with posterior fossa tumors required treatment for hydrocephalus (ultimately with ETV) in the cohort.

In some populations of patients with CNS tumors, the overall survival prognosis brings into question the ethics of hydrocephalus treatment. For instance, Roujeau et al. ${ }^{33}$ reported that in patients with hydrocephalus secondary to brainstem gliomas, the overall 1-year survival rate was $33 \%$, and the survival rate of patients with obstructive hydrocephalus was not significantly different from that of patients who did not develop hydrocephalus despite treatment. Given the overall poor prognosis in these patients, the need for CSF diversion as a whole must be counterbalanced with overall patient outcome and quality of life.

\section{ETV in Non-Posterior Fossa Tumors}

Most of the studies analyzed in this review investigated patients who underwent ETV for posterior fossa tumors; however, several studies reported results from ETV for those with lesions outside the posterior fossa. For example, Macarthur et al. ${ }^{22}$ reported a consecutive series of 61 neuroendoscopic procedures in 53 children with tumors, 47 of which were ETV for tumor-related hydrocephalus. Sixteen of the 53 tumors were cerebellar (30.2\%), whereas 13 were brainstem (24.5\%), 12 were third ventricular $(22.6 \%)$, 5 were thalamic or hypothalamic $(9.4 \%), 4$ were pineal $(7.5 \%)$, and 3 were classified as "other" location. Morgenstern et al. ${ }^{27}$ determined that none of the 15 patients who underwent ETV for pineal region tumors in their study required repeat CSF diversion procedures at the 6-month follow-up. Hayhurst et al. ${ }^{13}$ reported a small series of 11 patients who underwent ETV for hydrocephalus second- 
ary to cerebellopontine angle tumors, with 7 (63.6\%) of the patients remaining shunt-free at follow-up. Li et al. ${ }^{20}$ published a consecutive case series of 31 patients with tectal glioma and hydrocephalus (cohort age range 6 weeks-20 years), 18 of whom were treated with ETV, and 2 (11\%) of those 18 experienced ETV failure at long-term follow-up (median 8 years).

\section{Molecular Diagnostics and Tumor-Related Hydrocephalus}

New tools of molecular analysis have shed light on how different tumor subgroups may be more susceptible to developing hydrocephalus. For instance, Schneider et al. ${ }^{36}$ reported that in a cohort of 143 medulloblastoma pediatric patients, no patient with the Wnt tumor subtype required CSF diversion procedures (ETV or VPS), whereas $29 \%$ of Shh, $29 \%$ of group 3, and $43 \%$ of group 4 patients required CSF diversion. Therefore, molecular diagnostic techniques may aid in stratifying the need for CSF diversionary procedures for patients with tumors harboring a variety of molecular signatures.

\section{Limitations}

This study has several limitations. We only searched the PubMed database and may have excluded contributory literature contained in other sources. Most of the studies reported herein are single-center retrospective studies, which limits the generalizability of results and also implies significant heterogeneity in patient management and surgical decision-making. We did not perform a meta-analysis, which limits how the data presented can be quantified or interpreted with any statistical significance. Furthermore, we did not assess patient characteristics (e.g., age differences, tumor subtype), hospital size/case volume, or technical differences in ETV operations between studies (e.g., use of Fogarty balloons for wider fenestration), which may affect failure rates.

\section{Conclusions}

The use of ETV in tumor-associated hydrocephalus is largely heterogeneous with regard to indications, timing, and tumor subtypes. The failure rate of ETV for tumorassociated hydrocephalus in the studies with the largest patient populations ranges from $10 \%$ to $38.6 \%$. Although ETV has been reported to fail more than VPS in tumorassociated hydrocephalus in the short term, overall rates of success/failure may be similar over time, and the risk of infection appears to be lower in those patients undergoing ETV. Molecular tumor profiles may help predict those patients at higher risk of a CSF diversionary requirement associated with tumor resection. Nonetheless, treatment of tumor-associated hydrocephalus with ETV is relatively common (approximately 30\% to 55\% of all ETVs performed), and future studies are warranted to elucidate the role of ETV in this complex patient population.

\section{Acknowledgments}

We thank Kristin Kraus for editorial assistance with preparation of this manuscript.

\section{References}

1. Beuriat PA, Puget S, Cinalli G, Blauwblomme T, Beccaria $\mathrm{K}$, Zerah M, et al: Hydrocephalus treatment in children: long-term outcome in 975 consecutive patients. J Neurosurg Pediatr 20:10-18, 2017

2. Bhatia R, Tahir M, Chandler CL: The management of hydrocephalus in children with posterior fossa tumours: the role of pre-resectional endoscopic third ventriculostomy. Pediatr Neurosurg 45:186-191, 2009

3. Bouras T, Sgouros S: Complications of endoscopic third ventriculostomy. J Neurosurg Pediatr 7:643-649, 2011

4. Dewan MC, Lim J, Shannon CN, Wellons JC III: The durability of endoscopic third ventriculostomy and ventriculoperitoneal shunts in children with hydrocephalus following posterior fossa tumor resection: a systematic review and time-to-failure analysis. J Neurosurg Pediatr 19:578-584, 2017

5. Di Rocco F, Jucá CE, Zerah M, Sainte-Rose C: Endoscopic third ventriculostomy and posterior fossa tumors. World Neurosurg 79 (2 Suppl):S18.e15-S18.e19, 2013

6. El Beltagy MA, Kamal HM, Taha H, Awad M, El Khateeb $\mathrm{N}$ : Endoscopic third ventriculostomy before tumor surgery in children with posterior fossa tumors, CCHE experience. Childs Nerv Syst 26:1699-1704, 2010

7. El-Ghandour NM: Endoscopic third ventriculostomy versus ventriculoperitoneal shunt in the treatment of obstructive hydrocephalus due to posterior fossa tumors in children. Childs Nerv Syst 27:117-126, 2011

8. Feng H, Huang G, Liao X, Fu K, Tan H, Pu H, et al: Endoscopic third ventriculostomy in the management of obstructive hydrocephalus: an outcome analysis. J Neurosurg 100:626-633, 2004

9. Foreman P, McClugage S III, Naftel R, Griessenauer CJ, Ditty BJ, Agee BS, et al: Validation and modification of a predictive model of postresection hydrocephalus in pediatric patients with posterior fossa tumors. J Neurosurg Pediatr 12:220-226, 2013

10. Frisoli F, Kakareka M, Cole KA, Waanders AJ, Storm PB, Lang SS: Endoscopic third ventriculostomy prior to resection of posterior fossa tumors in children. Childs Nerv Syst 35:789-794, 2019

11. Fritsch MJ, Doerner L, Kienke S, Mehdorn HM: Hydrocephalus in children with posterior fossa tumors: role of endoscopic third ventriculostomy. J Neurosurg 103 (1 Suppl): 40-42, 2005

12. Furlanetti LL, Santos MV, de Oliveira RS: The success of endoscopic third ventriculostomy in children: analysis of prognostic factors. Pediatr Neurosurg 48:352-359, 2012

13. Hayhurst C, Javadpour M, O'Brien DF, Mallucci CL: The role of endoscopic third ventriculostomy in the management of hydrocephalus associated with cerebellopontine angle tumours. Acta Neurochir (Wien) 148:1147-1150, 2006

14. Kestle JRW, Riva-Cambrin J: Prospective multicenter studies in pediatric hydrocephalus. J Neurosurg Pediatr 23:135141, 2019

15. Kulkarni AV, Drake JM, Kestle JR, Mallucci CL, Sgouros S, Constantini S: Endoscopic third ventriculostomy vs cerebrospinal fluid shunt in the treatment of hydrocephalus in children: a propensity score-adjusted analysis. Neurosurgery 67:588-593, 2010

16. Kulkarni AV, Drake JM, Kestle JR, Mallucci CL, Sgouros S, Constantini S: Predicting who will benefit from endoscopic third ventriculostomy compared with shunt insertion in childhood hydrocephalus using the ETV Success Score. J Neurosurg Pediatr 6:310-315, 2010

17. Kulkarni AV, Drake JM, Mallucci CL, Sgouros S, Roth J, Constantini S, et al: Endoscopic third ventriculostomy in the treatment of childhood hydrocephalus. J Pediatr 155:254259.e1, 2009 
18. Kulkarni AV, Riva-Cambrin J, Holubkov R, Browd SR, Cochrane DD, Drake JM, et al: Endoscopic third ventriculostomy in children: prospective, multicenter results from the Hydrocephalus Clinical Research Network. J Neurosurg Pediatr 18:423-429, 2016

19. Lam S, Harris D, Rocque BG, Ham SA: Pediatric endoscopic third ventriculostomy: a population-based study. J Neurosurg Pediatr 14:455-464, 2014

20. Li KW, Roonprapunt C, Lawson HC, Abbott IR, Wisoff J, Epstein F, et al: Endoscopic third ventriculostomy for hydrocephalus associated with tectal gliomas. Neurosurg Focus 18(6A):E2, 2005

21. Limbrick DD Jr, Baird LC, Klimo P Jr, Riva-Cambrin J, Flannery AM: Pediatric hydrocephalus: systematic literature review and evidence-based guidelines. Part 4: Cerebrospinal fluid shunt or endoscopic third ventriculostomy for the treatment of hydrocephalus in children. J Neurosurg Pediatr 14 (Suppl 1):30-34, 2014

22. Macarthur DC, Buxton N, Vloeberghs M, Punt J: The effectiveness of neuroendoscopic interventions in children with brain tumours. Childs Nerv Syst 17:589-594, 2001

23. Madsen PJ, Mallela AN, Hudgins ED, Storm PB, Heuer GG, Stein SC: The effect and evolution of patient selection on outcomes in endoscopic third ventriculostomy for hydrocephalus: a large-scale review of the literature. J Neurol Sci 385:185-191, 2018

24. Miwa T, Hayashi N, Endo S, Ohira T: Neuroendoscopic biopsy and the treatment of tumor-associated hydrocephalus of the ventricular and paraventricular region in pediatric patients: a nationwide study in Japan. Neurosurg Rev 38:693704, 2015

25. Mixter WJ: Ventriculoscopy and puncture of the floor of the third ventricle: preliminary report of a case. Boston Med Surg J 188:277-278, 1923

26. Morelli D, Pirotte B, Lubansu A, Detemmerman D, Aeby A, Fricx C, et al: Persistent hydrocephalus after early surgical management of posterior fossa tumors in children: is routine preoperative endoscopic third ventriculostomy justified? J Neurosurg 103 (3 Suppl):247-252, 2005

27. Morgenstern PF, Osbun N, Schwartz TH, Greenfield JP, Tsiouris AJ, Souweidane MM: Pineal region tumors: an optimal approach for simultaneous endoscopic third ventriculostomy and biopsy. Neurosurg Focus 30(4):E3, 2011

28. Naftel RP, Reed GT, Kulkarni AV, Wellons JC: Evaluating the Children's Hospital of Alabama endoscopic third ventriculostomy experience using the Endoscopic Third Ventriculostomy Success Score: an external validation study. J Neurosurg Pediatr 8:494-501, 2011

29. O'Brien DF, Hayhurst C, Pizer B, Mallucci CL: Outcomes in patients undergoing single-trajectory endoscopic third ventriculostomy and endoscopic biopsy for midline tumors presenting with obstructive hydrocephalus. J Neurosurg 105 (3 Suppl):219-226, 2006

30. Ray P, Jallo GI, Kim RY, Kim BS, Wilson S, Kothbauer K, et al: Endoscopic third ventriculostomy for tumor-related hydrocephalus in a pediatric population. Neurosurg Focus 19(6):E8, 2005
31. Riva-Cambrin J, Detsky AS, Lamberti-Pasculli M, Sargent MA, Armstrong D, Moineddin R, et al: Predicting postresection hydrocephalus in pediatric patients with posterior fossa tumors. J Neurosurg Pediatr 3:378-385, 2009

32. Riva-Cambrin J, Kestle JR, Holubkov R, Butler J, Kulkarni $\mathrm{AV}$, Drake J, et al: Risk factors for shunt malfunction in pediatric hydrocephalus: a multicenter prospective cohort study. J Neurosurg Pediatr 17:382-390, 2016

33. Roujeau T, Di Rocco F, Dufour C, Bourdeaut F, Puget S, Rose CS, et al: Shall we treat hydrocephalus associated to brain stem glioma in children? Childs Nerv Syst 27:1735-1739, 2011

34. Ruggiero C, Cinalli G, Spennato P, Aliberti F, Cianciulli E, Trischitta V, et al: Endoscopic third ventriculostomy in the treatment of hydrocephalus in posterior fossa tumors in children. Childs Nerv Syst 20:828-833, 2004

35. Sainte-Rose C, Cinalli G, Roux FE, Maixner R, Chumas PD, Mansour M, et al: Management of hydrocephalus in pediatric patients with posterior fossa tumors: the role of endoscopic third ventriculostomy. J Neurosurg 95:791-797, 2001

36. Schneider C, Ramaswamy V, Kulkarni AV, Rutka JT, Remke M, Tabori U, et al: Clinical implications of medulloblastoma subgroups: incidence of CSF diversion surgery. J Neurosurg Pediatr 15:236-242, 2015

37. Tamburrini G, Pettorini BL, Massimi L, Caldarelli M, Di Rocco C: Endoscopic third ventriculostomy: the best option in the treatment of persistent hydrocephalus after posterior cranial fossa tumour removal? Childs Nerv Syst 24:14051412,2008

38. Texakalidis P, Tora MS, Wetzel JS, Chern JJ: Endoscopic third ventriculostomy versus shunt for pediatric hydrocephalus: a systematic literature review and meta-analysis. Childs Nerv Syst 35:1283-1293, 2019

39. Wong TT, Liang ML, Chen HH, Chang FC: Hydrocephalus with brain tumors in children. Childs Nerv Syst 27:17231734,2011

\section{Disclosures}

The authors report no conflict of interest concerning the materials or methods used in this study or the findings specified in this paper.

\section{Author Contributions}

Conception and design: Sherrod. Acquisition of data: Sherrod. Analysis and interpretation of data: all authors. Drafting the article: all authors. Critically revising the article: all authors. Reviewed submitted version of manuscript: all authors.

\section{Correspondence}

John R. W. Kestle: University of Utah, Salt Lake City, UT. neuropub@hsc.utah.edu. 